\title{
EN TORNO A UNA POÉTICA DE LA LENGUA
}

\author{
Eduardo Milán*
}

En términos generales, puede definirse la actitud de los movimientos de vanguardia históricos como una búsqueda de universalidad expresiva del lenguaje y como el ejercicio de una conciencia crítica del mismo. Ambas razones fueron practicadas desde posturas más o menos radicales, buscando siempre un acuerdo temporal o una simultaneidad operativa ante lo poético que posibilitara la coexistencia de la práctica en los distintos puntos de la cultura occidental. Sin embargo, aunque el impulso de la vanguardia es generoso y abarcador, totalizante e integral, no oculta a menudo su ambición hegemónica: Europa es siempre, desde el enunciado mismo de la condición vanguardista, el altavoz por el cual se expanden los principios rectores de lo que, por casi treinta años, se propuso en términos estéticos como una revolución completa. La poesía hispanoamericana recibe a las vanguardias históricas como una posibilidad de liberación al igual que en Europa. Pero, también, como una posibilidad de afianzamiento de la promesa de libertad que Rubén Darío inaugurara con la prédica modernista, una voluntad sincrética inusitada en términos de lenguaje poético hispanoamericano que por obra del poeta nicaragüense intenta, por primera vez, comulgar con el pasado histórico cultural de América Latina -elevado a categoría mítica de igual valor que la mitología greco-latina- al mismo tiempo que con la

\footnotetext{
* Departamento Académico de Estudios Generales, ITAM.
} 


\section{EDUARDO MILÁN}

fascinación futurista que la dinámica del progreso representa, especialmente en la atracción lumínica que a fines del siglo pasado ejerce París.

Quizás por paradoja, es la atracción por la poesía francesa la que permite el cambio que imprime Darío en la poesía española al modificar la métrica del verso con la inclusión de variedades practicadas en la poesía francesa, adaptadas al discurso poético castellano. Así, la apropiación de una visión del verso que se cultiva más allá de las fronteras del español permite redimensionar las fronteras de nuestra propia lengua lírica e introduce un nuevo aliento. Pero, básicamente, lo que introduce el poeta nicaragüense es la necesidad de modificación como condición de una búsqueda constante de medios expresivos, lo que definirá, en una buena parte, la razón de la poesía hispanoamericana de la primera parte del siglo Xx. No otra actitud es la de César Vallejo en Trilce (1922), la de Pablo Neruda en Residencia en la tierra (1925-1935), la de Vicente Huidobro en Altazor (1931) o la de Oliverio Girondo en su En la masmédula (1954), obras marcadas por una necesidad de exploración de los límites formales de la poesía de su momento que afectará el terreno de la lengua castellana, tanto en lo relativo a la invención de nuevos léxicos como en la consideración de la lengua como un territorio que necesariamente debe flexibilizar sus fronteras.

Esto es: la recepción de la vanguardia por los poetas hispanoamericanos que publican en los primeros cincuenta años o poco más del siglo XX prepara una visión de nuestra poesía como búsqueda de lenguaje nuevo y no tanto como certificación de una estabilidad del piso de la lengua, equilibrio que queda sistemáticamente cuestionado a lo largo de todas las prácticas poéticas occidentales por el influjo de las vanguardias históricas. Este hecho que parece irrefutable en lo general en la lírica occidental del siglo Xx, en América Latina parece indicar un parti-pris de desobediencia en relación a la gramática de la lengua española en tanto que revisa postulados de histórica corrección. No está de más decir que la poesía hispanoamericana del siglo Xx experimenta de manera profunda con los límites del lenguaje poético con una fuerza que no tiene antecedentes en la historia del castellano. 
Si bien este aluvión cuestionador del lenguaje poético es ubicable como voluntad dominante durante la primera mitad del siglo, sus secuelas se prolongan en la poesía hispanoamericana de la segunda mitad. Y si bien la generación de lo que podría denominarse herederos de la vanguardia -Octavio Paz, Nicanor Parra, José Lezama Lima o Gonzalo Rojas- ratifica en su producción acuerdos creados con la base crítica de nuestra producción poética, gran parte de sus obras va en busca de una reconsideración de la tradición por haber ubicado el agotamiento funcional del repertorio de la vanguardia que sus antecesores exploraron. Ese agotamiento, hay que decirlo, no lo es tan sólo en términos de repertorio formal de una poética de la vanguardia. Es también el agotamiento de la idea de una modernidad totalizante que en Occidente comienza a manifestarse en las décadas de los sesenta y setenta con el auge de los movimientos contraculturales y estudiantiles que cristalizaron en 1968. Y en América Latina, gracias al influjo del proyecto de liberación social que promete la Revolución Cubana poco después de tomar el poder en 1959. Este hecho histórico es contundente para la realización práctica de una conciencia libertaria que estuvo presente en los intelectuales hispanoamericanos a lo largo del siglo.

El descreimiento en una modernidad eufórica que empieza a tomar relevancia como pensamiento en Europa tiene una alternativa positiva en América Latina por la esperanza que inaugura el socialismo cubano. Sin embargo, muy poca de la poesía que se escribe en América Latina en esos años alcanza el nivel de calidad de la poesía de sus precursores inmediatos. Las excepciones la dan poetas mayores: Juan Gelman, Ernesto Cardenal o José Emilio Pacheco logran crear obras que conjugan conciencia política e histórica con búsquedas de alternativas lingüísticas. Pero la línea dominante de la poesía llamada "comprometida” es víctima de la urgencia histórica. Su lenguaje, fuertemente coloquial y unívocamente referencial, parece desoír las enseñanzas de una de las obras poéticas mayores de la poesía hispanoamericana de mitad del siglo, la del chileno Nicanor Parra. La publicación en 1954 de Poemas y antipoemas da un giro en nuestra poesía al cristalizar una serie de preocupaciones que alentaban en la poesía hispanoame- 


\section{EDUARDO MILÁN}

ricana y no sólo en ella: el lugar del hablante poético, el lugar de la poesía y su función, la situación del lenguaje lírico a mediados de siglo. Poemas y antipoemas asume una realidad de la poesía del siglo XX que es irrefutable: su diálogo con la historia. A la vez plantea los límites poéticos del lenguaje coloquial y señala la condición gastada de una buena parte del lenguaje lírico hispanoamericano, en especial la del influido por el surrealismo francés.

Si se interpreta la publicación, en 1941, de Laurel. Antología de la poesía moderna en lengua española, firmada por dos poetas hispanoamericanos, Xavier Villaurrutia y Octavio Paz, y por dos poetas españoles, Juan Gil Albert y Emilio Prados, como la afirmación de la idea de un suelo lírico común de nuestra lengua se interpretará correctamente. Se reúnen allí poetas modernistas o pre-vanguardistas y poetas que ya están insertos en una dinámica transformadora de la poesía en nuestra lengua. Sin embargo, la fecha de publicación de la antología señala entrelíneas lo que los autores no logran revelar: la diferencia real de la situación en la que se encuentran en ese momento los países hispanoamericanos, que flotan en una atmósfera liberal aunque cada vez más inquietante, y España, hundida en el franquismo. Una lectura histórica, por no decir política de la antología señalaría una actitud de solidaridad de la zona "liberada" de la lengua con la zona amordazada de la misma. En efecto, no hay grandes desniveles planteados todavía en lo que concierne a libertad de expresión poética. Pero, para un lector de poesía sensible a los acontecimientos históricos resultaría al parecer difícil extrapolar a la poesía de una condicionante tan precisa del lenguaje poético como la realidad política, social y cultural de una dictadura. La sombra de esa censura también podría verificarse en la lectura por parte de un extranjero de la poesía escrita en Uruguay en el lapso de la dictadura de 1973-1985.

Toda poesía, aún la más teórica, abstracta o vaga en su consideración lingüístico-referencial acusa recibo de la vivencia del poeta que la escribe. El mundo está siempre en el poema, manifiesto de mil maneras. El poeta controla su actualización en el texto hasta donde puede, no hasta donde quiere. Aún en el caso de la obra poética de José Lezama 
Lima, caracterizada por el impulso crítico-órfico de devolver la historia a un espacio mítico-simbólico, la realidad se presenta como mundo realmente existente. Así vistas las cosas, la poesía española escrita bajo el franquismo supone una lectura bajo apercibimiento, no una sublectura tal vez, pero sí una lectura que impone una preconciencia situacional del marco contextual en que esa poesía se escribe e inscribe. Esto, claro está, observado desde la óptica hispanoamericana que ve en la poesía una práctica de la libertad, ya sea de libertad expresiva o constructiva. Se puede leer libertad en la poética de la celebración de Claudio Rodríguez. Su poesía, mediante esa tentativa de vuelo intenta atravesar toda malla referencial que aluda a hechos puntuales e históricos. Se puede leer y se lee libertad en la poesía de Antonio Gamoneda: la introspección de su habla se relaciona de forma inédita con los elementos del afuera y crea una atmósfera espacial dialógica en la que los niveles de interioridad y exterioridad parecen anularse. O en las poéticas donde trabaja Juan Eduardo Cirlot: la vocación experimental de su poesía en cuanto al tratamiento lingüístico que propone en alianza estrecha con la necesidad de creación de un espacio mítico del habla o de recreación del mismo, señala el intento de fusión de una memoria anterior a la historia inmediata -la forma imagística propuesta por una de las vanguardias dominantes, el surrealismo- y la visión de lo poético como universo intemporal, simbólico.

¿Qué decir de otros poetas reunidos arbitrariamente -como señala Miguel Casado- bajo el estigma generacional de "generación de los 50”? Empresas como la de Ángel González deben ser ubicadas como deudoras de la contingencia histórica. El uso del lenguaje poético, por más irónico y humorístico que pueda resultar en su empeño de crítica social y desacralización de lo poético, es absorbido por el aparato ideológico que pretende cuestionar, que necesita del facilismo retórico y con él se hace fuerte. Lejos estamos en este ejemplo de una propuesta de acuerdo entre crítica política y conciencia estética como la llevada a cabo por Blas de Otero, un poeta emblemático de la poesía de resistencia ante la sociedad franquista. No se trata, parecería, en la lectura de los poetas de la posguerra española, de elegir entre actitudes puras 


\section{EDUARDO MILÁN}

o actitudes contaminadas ante el hecho poético o el poema. Se trataría, mejor, de distinguir entre temperaturas estéticas altas y bajas, entre conciencias agudas del hecho poético y conciencias superficiales. La Guerra civil española y sus secuelas parecen trazar un parteaguas entre la disponibilidad abierta a todos los repertorios anterior al conflicto -cuya pauta histórica inequívoca parecen marcar los poetas nombrados como del 27- y la posteridad al conflicto caracterizada por la cerrazón histórica y la censura que obligan a la cautela en el tratamiento formal del lenguaje y en el manejo de los contenidos y, en muchos casos, al exilio de los poetas. Pero el exilio es otra situación. La consideración del hecho poético -en lo que concierne al exilio externo-pasará por la reconsideración imperiosa del lugar de la poesía, de la posibilidad de nombrar y de la asunción desnuda de lo que la poesía es en esencia. Muchas veces el exilio ha significado un crecimiento sustancial en la poética de los autores, como en el caso del poeta argentino Juan Gelman. Pero la pregunta en realidad es: ¿cómo señalar semejanzas y diferencias de actitud ante el hecho poético entre realidades históricas que posibilitan el ejercicio de la palabra poética y realidades históricas que la bloquean?

En 1970 el poeta peruano Rodolfo Hinostroza gana el premio, otorgado en España, “Maldoror” de poesía con Contranatura. Este texto representa una renovación de la poesía hispanoamericana. Es un libro que desafilia al poeta de toda voluntad de poder en términos de dominio y al mismo tiempo enjuicia las expectativas sociales de América Latina de un ingreso a la modernidad. Poesía formalizada en verso proyectivo y bajo un severo rigor de dicción heredado de Ezra Pound, Contranatura refresca la memoria de la poesía hispanoamericana en relación a una influencia muy cara a su tradición: la de la poesía norteamericana. El influjo de la poesía norteamericana en la de América Latina se remonta a Darío y a su reconocimiento en la “Oda a Roosevelt”, poema que integra Cantos de vida y esperanza (1905), de la posición fundamental que ocupa Walt Whitman en la poesía de fines del siglo XIX y principios del XX. Si bien no es Darío quien asimila la influencia de la poesía norteamericana en su lenguaje, son poetas nicaragüenses 
posteriores los que allanarán el lenguaje poético hispanoamericano con ese aire nuevo que implica una visión pragmática de la lengua y de sus referentes. Luego del paso de la vanguardia, la dicción poética dominante en América Latina se había retrotraído a la influencia dura de los maestros del Siglo de oro español. La metáfora fue condición sine qua non para que se pudiera hablar de poesía. Los nicaragüenses Carlos Martínez Rivas y Ernesto Cardenal, bajo la rectoría de su compatriota José Coronel Urtecho, se abren a la condición inmediata y cotidiana del verso en su aprehensión del mundo. Pero la apertura que propicia la poesía norteamericana en su influencia no se limita a un cambio en la retórica. Para la poesía que cultivan Pound, William Carlos Williams y sus descendientes el poema se plantea como el territorio de la libertad referencial. La poesía deja de estar codificada en sus motivos y permite el ingreso del entorno cultural de la época. El hecho implica una modificación grave en tanto supone un desligamiento de la tradición poética hispánica. La coloquialidad del lenguaje exige referentes dinámicos, verificables en el contexto social inmediato. Y se los encuentra en un ahí también inmediato y cada vez más desbordado: en los estímulos icónicos de la sociedad de consumo.

La secularización radical que implica la sociedad de consumo como manifestación epidérmica de un proceso profundo de cosificación y alejamiento del nivel espiritual de la vida humana penetra en el poema. Si hay gracia, como en los casos de Martínez Rivas o Hinostroza, se respira un aire fresco en la lectura. Si no la hay dominará una atmósfera nocturna, fantasmática y sofocante. Los signos del consumo son sólo la representación superflua del modelo de vida norteamericano que suele penetrar detrás del lenguaje en su consideración estética. En la poesía norteamericana ingresa como parte de un contexto referencial real; en la hispanoamericana como nostalgia de un igual imposible y, en el mejor de los casos, como parodia. La consideración del poema como territorio donde "todo cabe", divisa clara en los Cantares de Ezra Pound, puede traer consecuencias funestas en oídos inexpertos. Los signos del consumo pueden ser utilizados en el texto poético como crítica de la solemnidad de la dicción poética clásica, asimilada gene- 


\section{EDUARDO MILÁN}

ralmente como manifestación intemporal o arcaica. Pero visto el hecho con mayor profundidad, se trata de la aspiración ingenua de los signos del consumo de sustituir la condición simbólica de motivos y emblemas caros de la poesía de cualquier época, en olvido flagrante de su relación arquetípica con la psique.

Esta política de sobresaturación referencial del campo del poema es frecuente en uno de los últimos movimientos de la poesía hispanoamericana, el movimiento neobarroco creado en 1986, también llamado por Néstor Perlongher, uno de sus fundadores, neobarroso, en atención al sustrato lamoso del Río de la Plata, agua divisoria de Montevideo y Buenos Aires, lugar de nacimiento de Perlongher. El movimiento cuenta a su favor con una salvedad que, en la mayoría de sus exponentes, impide la caída en la banalidad y en lo frívolo: la alta competencia intelectual y performativa de sus integrantes, empezando por el mismo Néstor Perlongher. José Kozer, Roberto Echavarren, Eduardo Espina, Arturo Carrera, son algunos de los poetas que la crítica reúne alrededor de una denominación que sintetiza en la poesía conceptualizaciones que derivan de la visión barroca de la poesía hispanoamericana de José Lezama Lima, de la interpretación del barroco como transculturación que realiza el poeta y ensayista brasileño Haroldo de Campos -uno de los fundadores, junto a su hermano Augusto de Campos y Decio Pignatari, del movimiento de Poesía Concreta de Sao Paulo en 1952-, y de la recuperación de una cierta recepción de la vanguardia hispanoamericana, en especial de Oliverio Girondo en su fase radical de En la masmédula.

Para intentar tipificar al poema neobarroco habría que señalar su característica descentrada e incluso atemática, su condición productiva proliferante que se sostiene a menudo en el encadenamiento paronomástico y que recuerda por momentos las líneas de fuerza trazadas para la consideración de un texto rizomático esbozadas en Mil plateaux (1980) de Gilles Deleuze y Félix Guattari. Se trata de la consideración del poema como instrumento de crítica al poder, como dispositivo textual subjetivo y desalienante para desmantelar códigos culturales opresivos, no ya como objeto de arte. Sin embargo, en la mayoría de 
los poetas citados y en otros, como los mexicanos David Huerta y Coral Bracho, una pulsión fuertemente lírica re-encamina el poema a un diálogo con la tradición. Queda de todos modos planteado el dilema de las posibilidades de continuidad del poema abierto en su forma como correlato estético de una realidad social que se ofrece, en su consideración superficial, de igual manera ante los ojos desprevenidos. El poeta hace uso de esa simulación y enfrenta al mundo con lógicas representativas similares por considerar que el poema tradicional se sustrae al enfrentamiento al hablar un código específico. ¿No existe, sin embargo, el peligro, en poéticas de este tipo, de una desafiliación radical de lo poético en aras de una polémica con la realidad cultural y social e incluso política? ¿No puede el descreimiento en el uso de un "lenguaje exclusivo" hacer perder de vista el objetivo principal de la poesía, su apuesta esencial? ¿No hay algo aquí del dilema al que se habrían enfrentado los "novísimos” poetas españoles reunidos en Nueve novísimos (1970) de José M. Castellet?

Al margen de la frecuente -y muy probablemente sensata- calificación de la antología de Castellet como otra de esas antologías preparadas por el mercadeo editorial más que por una razón unitaria real, la presencia en aquel texto de poetas como Félix de Azua, Guillermo Carnero, Pere Gimferrer o Leopoldo María Panero impide hablar de superficialidad. El aire nuevo que traen los “novísimos” al escenario poético español parece estar en relación directa con la apertura a la realidad social vista en términos de cultura. La poesía se vuelve testimonio de un tiempo histórico preciso, el presente, y el poema absorbe sus características de manera inmediata. La historia en su presentificación parece ser una concesión al pasado. Y la poesía, salvo muy precisas excepciones -las mencionadas, que tampoco escapan a la devoción por ese presente autofágico- va paulatinamente abandonando su relación con la memoria, ese motor que impide, entre otras cosas, el soslayamiento de lo terrible. No hay madurez de voz poética en los poetas de Castellet. Eso lo lograrán más tarde, solos. La madurez parece estar fuera de serie, al margen de la antología y de la generación, en poetas de la misma edad que los antologados, como en José Miguel 


\section{EDUARDO MILÁN}

Ullán. Pero lo que aparece allí en forma inequívoca son los trazos magnéticos del presente cultural en la pantalla de una memoria que se va perdiendo.

Los ejemplos de Contranatura de Hinostroza y dieciséis años más tarde la de los “neobarrosos” conosureños parecen ser cancelaciones de un modo de la poesía de nuestra lengua de relacionarse con el pasado. El agotamiento de la actitud de las vanguardias -no así el de sus repertorios, que son utilizados en la poesía actual como otras de las formas posibles- el agotamiento de modos de responder a realidades adversas de índole social o político por parte de la poesía -no el agotamiento de la necesidad de responder, especialmente en sociedades como las hispanoamericanas que oscilan entre las asunción de un pasado histórico indigente y el reconocimiento de un futuro de interdependencia cada vez más creciente, por el cual deberán luchar a partir de la necesidad básica de su reconocimiento como otro-, plantean en la poesía hispanoamericana la encrucijada del posible seguimiento. A fines de siglo los proyectos poéticos colectivos habían desaparecido y, con ellos, las posibilidades de concebir la poesía desde el punto de vista de un lenguaje en transformación e, incluso, de un lenguaje de anticipación (concepción en la cual mucho jugaron ciertas vanguardias históricas, en particular la soviética). Esta crisis de la poesía como lenguaje necesariamente implicaría una reconcepción de la poesía en términos de lengua y en términos de lo que ese reconocimiento atrae: la rehabilitación de las nociones de tradición.

Si bien la poesía hispanoamericana y la española compartieron siempre el mismo piso de la lengua, las distintas circunstancias estéticas e históricas las obligaron a hablar en escenarios distintos. La afiliación de un sector importante de la poesía hispanoamericana a los estímulos de las vanguardias tuvo la implicación, aunque indirecta, de un soslayamiento de la tradición poética española. Y la crisis de aquella afiliación, impuesta también por la realidad histórica, no necesariamente habilita al reconocimiento de la tradición española. La tradición poética española es, para la poesía hispanoamericana -que intentó recrearse a sí misma en forma continua desde la fundación dariana-, 
una tradición más. Puede ser reconocida a partir de ejemplos emblemáticos como el de san Juan de la Cruz por poetas como el venezolano Rafael Cadenas. Pero la poesía de Cadenas siempre sostuvo ese principio escritural de retracción; llegar a san Juan era llegar al mejor de los puertos posibles.

A la poesía española, en cambio, siempre le queda la posibilidad de rehabilitar sus fuentes, con el peligro continuamente presente de un regreso anacrónico al pasado. Ambas manifestaciones poéticas tomadas en conjunto podrían encontrarse en la búsqueda de una palabra esencial o, dicho de otro modo, en la empresa de des-instrumentalizar el lenguaje poético. Cuestión difícil para la poesía hispanoamericana, que habita un piso de historia no resuelta. 
